\title{
Si se puede construir desde la escuela una mejor sociedad
}

\author{
Elsi Janeth Benitez \\ Recibido: 04 de agosto 2011 \\ Aceptado: 03 de noviembre 2011
}

¿Cómo transformar el aula de clase en ambientes del entorno y construir una mejor sociedad desde aquel lugar? ¿Cómo transformar este espacio para lograr un alto grado de motivación y liderazgo en los niños, potenciar el desarrollo de sus dimensiones y entrelazar el currículo con la realidad?

Se ha podido constatar que los niños en la actualidad muestran un alto índice de violencia en la resolución de sus problemas, una falta de pertenencia hacia el entorno y la naturaleza, baja autoestima, poca disposición para llevar a cabo actividades que necesiten esfuerzo y una rebeldía temprana que se refleja en los distintos ambientes. Por tal motivo, es importante crear espacios que les permitan expresarse y potenciar en cada uno aquellas aptitudes y actitudes. Así, estarán en capacidad de transformar y trascender dentro de una comunidad.

Según Feuerstein (---), los cambios educativos en la sociedad multicultural, globalizada y de la información, obligan a la escuela a reencontrarse, a restaurar su interior y a repensar su sentido y su función social. Esto, en tanto los factores que llevan a los niños a estas situaciones están relacionados con los estereotipos que a diario les son mostrados por distintos medios como la televisión, la radio y los video juegos; además de la fría y temprana soledad a la que se enfrentan por las ocupaciones de sus padres, a la ruptura entre ellos y al rol equivocado de ellos frente a sus hijos -quienes a pesar de aparentar tenerlo todo, en realidad tienen muy poco.

Por esto la escuela debe ser transformadora de la sociedad, desarrollando en los niños la capacidad de defender los derechos humanos y de traspasar las paredes del aula para renovar lo tradicional a favor del bien común. Todo esto puede ser posible si se crean ambientes de confianza, aceptación, respeto, reflexión, diálogo, solidaridad, viviendo experiencias significativas dentro del aula que favorezcan 
su capacidad de convivir en paz a pesar de las diferencias con el otro. Es importante entonces que al estudiante se le permita ser parte del mundo, conocer sus proyectos, sus problemas, su responsabilidad en el progreso y conservación del medio, y que proponga acciones desde el aula para favorecer la convivencia en la época y momento que les tocó vivir. . Aprender a ser.

Por tal motivo, es importante lograr que los niños se proyecten en la futura sociedad como líderes, mandatarios, constructores de paz; que además se apropien de un rol dentro del ámbito en el que se desempeñen, permitiéndoles solidificar sus bases y tener una nueva visión acerca de la sociedad. Ante lo mencionado, he estado trabajando y perfeccionando una estrategia pedagógica que consiste en transformar el aula en ambientes del entorno donde los niños conozcan la realidad del país, opinen, analicen y den soluciones. El objetivo es que ellos asuman roles de la cotidianidad a través de experiencias significativas que les permitan interpretar un papel protagónico y de liderazgo frente a la problemática del país.

Con esto se busca que los niños, ya desde preescolar, se construyan como seres más tolerantes, responsables, comprometidos, como mejores ciudadanos, mejores amigos, mejores hijos, mejores hermanos, futuros mejores padres. También como esposos y trabajadores críticos, reflexivos, conscientes de que son los arquitectos de una sociedad mejor y feliz. En pocas palabras, los niños aprenderán a tomar pequeñas grandes decisiones que dejen huellas en su formación.

La lectura de noticias del periódico es una de las estrategias que se utiliza con el fin de que los niños no sean ajenos a la realidad del mundo y puedan realizar críticas y dar opiniones al respecto por medio de una orientación adecuada de padres y maestros. Las noticias son leídas en familia, después se socializan en una puesta en común donde cada uno expresa qué haría para solucionarlas; luego se recogen y un niño asume el rol de voceador, vendiéndolas al grupo. Así, cada uno cambia la noticia y se enteran de lo que sucede. Esto permite que los niños no sean ajenos a la realidad y que se interesen por la lectura. De tal forma, aunque el proceso se encuentra en una etapa inicial, existe en los niños un interés por temas del país: sienten que pueden ser agentes de cambio cuando dan soluciones e interactúan con seguridad. Temas como el TLC lo asocian con hacer las cosas con calidad, conocen sobre la pobreza, falta de trabajo, el Protocolo de Kioto y los tratados sobre medio ambiente, fenómenos naturales y se sienten parte activa del cuidado de la naturaleza y del cambio.

El objetivo de la estrategia es, finalmente, retomar los temas más relevantes para profundizar sobre su compromiso con el cambio desde su posición de niños, creando así un pensamiento social que también está inmerso el horizonte institucional de los colegios. Según Pablo Romero Ibañez (---), tal estrategia no sólo permite representar significaciones, sino que desarrolla la habilidad para interactuar afectiva y efectivamente en sociedad en tanto el aula de clase se 
convierte en un espacio de tolerancia que contribuya a la construcción colectiva y progresiva de una sociedad moderna, solidaria y comprometida. De tal modo, es posible comprobara diario que el aula es el mejor escenario para aprender a vivir en paz, vivenciar valores y donde se posibilita la transformación de la realidad a través de un aprendizaje significativo y autónomo (un lugar donde el currículo y la realidad se entrelazan).

De esta manera, un día el aula de clase se puede transformar en la casa: se organiza como tal y se asumen los roles de los miembros de la familia; cada niño trae de casa los elementos necesarios para interpretar su papel a través del cual se pretende conocer la realidad de cada uno, y espontáneamente cuentan sus experiencias familiares. Así se descubren las necesidades afectivas que muchas veces no expresan los niños. Una de las tareas consiste en llamar a los abuelos y otros familiares, saludarlos, compartir lo que han aprendido dentro del aula, logrando que los niños aprendan de las experiencias familiares, lo que hace a su vez que las familias se unan.

Otra de las actividades que se pueden llevar a cabo dentro del aula es invitar a los abuelos de los niños a compartir con ellos y contarles sus experiencias. Comparten una merienda, cuentan cuentos, juegan, etc. Esta actividad tiene como lema «Abuelitos no se vayan de la escuela» y se pretende lograr un aprendizaje en colaboración con la familia, sabiendo que ella es el núcleo de nuestra sociedad (identificando los modelos de familia actuales, para no lastimar a los niños). A través de esta experiencia llevo a los niños, en la mayoría de los casos, a establecer diálogos críticos con sus padres y familiares, o que origina cambios paulatinos dentro del núcleo familiar, convirtiendo al niño en un agente de cambio desde pequeño.

Teniendo en cuenta los planteamientos de Piaget (---) sobre la importancia de la experimentación y el contacto del niño con el medio, el aula también se puede convertir en una huerta o plaza con productos que previamente los niños han sembrado en la huerta del colegio, complementándolos con otros alimentos que se traen de casa. Los niños empiezan esta actividad asumiendo el rol de campesinos y dialogan teniendo en cuenta sus referentes acerca de la problemática actual de desplazamiento, la pobreza, la falta de oportunidades a las que se ven expuestos los campesinos colombianos. Luego los estudiantes dan alternativas de solución que contribuyen a la creación de una política social desde el aula, erradicando la indiferencia ante el dolor ajeno. Finalmente se organizan los productos, clasificándolos según sus características (color, forma, textura, etc.) y adicionalmente se realizan visitas a plazas de mercado donde los niños y sus familias reconocen alimentos y dialogan. http://sociedad alaulaproyeccionsocial.wikispaces.com/

Los niños se convierten entonces en compradores y vendedores que toman decisiones, con lo cual ponen en práctica las normas básicas de convivencia en 
sociedad: saludar, respetar el turno, dar las gracias, colaborar, ser solidarios, darle el turno a los ancianos y a las damas. El dinero lo remplazan por fichas de colores y de ese modo el aula se transforma en un supermercado, una tienda, un restaurante etc. Para estas actividades se utilizan empaques vacíos de la canasta familiar, así, además de reutilizarlos, se potencia la lectura, se asumen roles y se integran todas las áreas.

El aula puede ser incluso un Transmilenio, una calle, un puente, un tablero de ajedrez donde los niños son las fichas y en el que todo es un aprendizaje para la vida. De igual manera, cada niño asume un rol de líder en el aula con una función específica, la cual cumple con agrado diariamente. Con lo anterior se reafirma el planteamiento de Miguel de Zubiría (---) acerca de la necesidad de desarrollar en el currículo el amor a sí mismo, al mundo y al conocimiento, el cual no debe llegar por imposición sino por seducción, motivación e interacción afectiva en la cotidianidad escolar.

Los resultados no se hacen esperar. Gracias a las diferentes actividades y al compromiso de padres de familia y docentes, al interés manifestado por los niños y especialmente al ambiente de afecto en el que aprenden, ellos adquieren fácilmente y con propiedad, cada uno de los conocimientos aprendidos. Esto lo demuestran al aplicar lo aprendido en diferentes espacios, particularmente en la resolución de diversos problemas en su cotidianidad donde sus desempeños están impregnados de propiedad y acierto y donde se generan situaciones de éxito que fortalecen su autoestima y seguridad. Dichos resultados son un punto de referencia para ser cada día mejores con el lema «hoy soy mejor que ayer y mañana mejor que hoy».

Para evaluar los logros académicos y de convivencia es importante realizar una evaluación continua, acompañada de la retroalimentación inmediata que les permite a los niños caer en cuenta del error y aclarar dudas. Así es posible lograr un buen aprendizaje, de tal forma que la evaluación de los estudiantes se convierte en la auto evaluación del maestro. Se dan las explicaciones que sean necesarias con diferentes estrategias, hasta lograr el aprendizaje de todos con actividades divertidas y motivantes como las mencionadas anteriormente. Se logra, además, que los niños que comprendieron desde el comienzo, retroalimenten y se conviertan en monitores, y los que no entendieron aclaren los conceptos hasta lograr que la totalidad del grupo aprenda (y no quede un niño sin alcanzar la comprensión de lo aprendido) .Aprender para la vida..

Además de las guías y trabajos diarios, se diseño un instrumento de evaluación que consiste en un plano cartesiano en el cual se hace uso de la estadística lúdica. En este plano, a través de la integración de todas las áreas del conocimiento, se puede ver la evolución completa del proceso de aprendizaje y retomar los temas relevantes, entrelazándolos y aplicándolos en situaciones concretas. Aquel instrumento puede ser trabajado en grupo e individual, dando 
oportunidad para aprender a escuchar, caer en cuenta del error, aceptar la diferencia fortalecer el sentido de responsabilidad y el trabajo en equipo. Esta actividad pretende, en definitiva, valorar el esfuerzo de cada uno y ciertamente ha tenido resultados exitosos debido a lo atractivo y divertido; a su vez el niño vivencia valores y fortalece su relación con los demás y aprende del error.

El cambio de los niños es evidente, a partir de estas experiencias y la huella se refleja año tras año. Parte de los resultados de este proceso se muestran en los modelos de vida que este proyecto ha logrado forjar, apoyando el horizonte institucional en su misión, visión, principios y valores. Por otra parte, esto logros se reflejan en aspectos claves: una buena convivencia, hacer las cosas bien, interés por conocer la realidad, establecimiento de relaciones interpersonales basadas en valores; todos ellos ingredientes esenciales para construir una mejor sociedad.

Lo anterior lleva a enamorarme más de la profesión y a ser consciente de la responsabilidad que tienen los maestros en la construcción de un mundo mejor, porque lo importante es que los niños crezcan teniendo la seguridad de que las cosas importantes para la vida se aprenden cuando se es niño (Robert Fulhghum, ---). Niños y maestra aprenden a diario en un ambiente de amor y aceptación de las diferencias, mostrando desde pequeños que son agentes transformadores de la sociedad. Y un día cuando sean presidentes, senadores, papás, recordarán que se construyeron desde pequeños como mejores seres humanos. Las familias han sentido el impacto de la propuesta cuando algunos hogares replantean su relación y comienzan de nuevo, con cambios que se hacen evidentes.

El proyecto día a día demuestra que sí vale la pena aplicarlo. Los niños en su cotidianidad evidencian el aprendizaje, su nivel de convivencia es muy bueno, expresan la alegría en cada actividad que realizan, asumen roles con facilidad, manifiestan autonomía y a medida que transcurren los años muestran la huella de haber sido parte de él.

El buen trato es el ingrediente principal de las relaciones interpersonales. Los trabajadores del colegio son esenciales en esta formación puesto que los niños los saludan con afecto, les llaman por su nombre, les agradecen su esfuerzo y dialogan con ellos. Estas diferentes actividades se fortalecen la capacidad de asombro y hacen que se mantenga el interés. Así mismo, los niños aprenden que las dificultades se resuelven a través del diálogo, la auto evaluación, la evaluación y laco-evaluación, aspectos que se fortalecen continuamente y que hacen del aprendizaje un proceso integral.

Gracias a la diversidad de las actividades se incrementa paulatinamente el querer aprender y los estudiantes profundizan más sobre los temas, lo que causa al mismo tiempo un aumento en la participación durante las clases. Igualmente la organización se vuelve parte de los estudiantes, el sentido de grupo aumenta notablemente y los niños se apegan más al concepto de«el éxito de uno es el éxito 
de todos», siendo siempre conscientes de que las metas se logran más fácilmente si hay un compromiso personal y colectivo.

El fortalecimiento del liderazgo es notorio con esta estrategia, lo que hace que los estudiantes sean niños seguros, que tomen decisiones y que desde pequeños busquen participar en el gobierno escolar con gran propiedad y convencimiento. Esto se evidencia en sus propuestas llenas de seguridad y compromiso, producto de la motivación que trae esta vivencia. Es el caso especial del personerito del año anterior, quien asombra con su actitud frente al compromiso adquirido.

Comenzar con la construcción del proyecto de vida de los estudiantes desde temprana edad, hallando sentido a un mundo poco evidente y maravilloso a la vez, y con el fin de que la escuela se vuelva atractiva y apetitosa, quiero seguir siendo maestra de vida: busco que los niños le encuentren sentido a la vida.

La meta es realizar esta transformación en las aulas y hacerla trascender a otros colegios e instituciones. Los procesos metodológicos van acompañados con las TIC, que forman parte de la cotidianidad de los niños (aula virtual del colegio) y de la incursión a páginas que apoyan y complementan los temas con sus familias. ¿Ahora cree usted que la transformación de la sociedad es solo cuestión de adultos o debe comenzar desde niño? http://recursos-juegos.blogspot.com/ 